\title{
MAPPING AND ORDERED CLONING OF THE HUMAN X CHROMOSOME
}

Final Progress Report

March 1991 - February 1995

C. Thomas Caskey, M.D., PI

Department of Molecular and Human Genetics

Baylor College of Medicine

Houston, Texas 77030

September 1995

PREPARED FOR THE U.S. DEPARTMENT OF ENERGY

UNDER GRANT NUMBER DE-FG03-88ER60692 


\section{Progress $3 / 1 / 94-2 / 28 / 95$}

The final year of funding provided to Dr. Caskey was used to develop and further elaborate the reciprocal probing method devised by $\mathrm{Dr}$. Caskey and Dr. Cheng Chi Lee of BCM. A publication describing the results of this pilot study appeared in a recent issue of Human Molecular Genetics (Lee et al., 1995).

Briefly, the method entails the use of pooled cDNA probes to arrayed chromosome-specific cosmid libraries (prepared by the national gene library project of LANL or LLNL) to identify cosmids containing sequences capable of hybridizing with a cDNA clone in the pool. Cosmid clones are isolated and used as probes to identify specific cDNA clones, and the CDNA and cosmid are paired. Sequence of the cDNA insert and FISH-based mapping of the cosmid clone provide a possible identity and location for each.

In this pilot study, placental cDNA clones from a library prepared by Dr. Lee were used to identify cosmids from both chromosomes $X$ and 17. Sixty unique cDNAs were identified, of which 22 were novel when compared with the sequence databases while another four cDNAs showed homologies to ESTs. Thirty-four CDNÁs showed significant homology to previously described eukaryotic genes. Of the described gene matches, 26 were from human while the remainder were homologous to rodent, chicken and nematode sequences. The average size of the cDNA inserts was $1.5 \mathrm{~kb}$. Nine cDNA clones (xp161, xp22G3, 6B10, 2D9, 2E8, 9F3, 12B5, 15C8, 24F3) contained both the published $5^{\prime}$ and $3^{\prime}$ ' untranslated regions of the corresponding genes, demonstrating that they contain the complete protein coding region of their respective mRNAs. This pilot study identified eight genes previously mapped to the $X$ chromosome and eight mapped to chromosome 17, suggesting that it is a viable technique for identification of chromosome-specific genes (Tables 1 and 2). Some items of interest were found in these data. Four cDNAs (5G12 and xp278 in Table 1 and 3G12 and 8D1 in Table 2) identified cosmids mapping to two or more locations on the chromosome. These may represent members of gene families, pseudogenes, etc., and provide a measure of the selectivity of the method. As this is a hybridization-based approach, it provides the ability to identify imperfect matches between cDNA and genomic clone. While this generates uncertainty regarding the derivation of the CDNA, it offers the opportunity to identify chromosome-specific genomic clones containing sequences related to the cDNA, which may be interesting in themselves. This is also seen in the identification of cosmids by cDNAs that are clearly not X-linked (cytokeratins 8 and 18, for example), but identify homologous $X$ clones (An X-linked locus homologous with cytokeratin 18 has been previously reported. The method offers a rich source of genomic clones for analysis, and the cDNAs identified are also of interest, but with caution regarding authentic map position.

The efficiency of the reciprocal probing strategy was estimated through analysis of the 32 chromosome 17 genes identified in the pilot study. The 2592 randomly isolated placental cDNA clones were pooled as probes and identified 278 cosmids from the 20,000 clones in the Los Alamos chromosome 17 (LA17NC01) cosmid library. Of these, 75 could not be associated with a CDNA and appear to have been false positive clones. The remaining $203(73 \%)$ cosmids were true positive signals as identified by pooled cDNA probes. Hybridization with individual cDNAs separated the 203 cosmids into 35 non-overlapping groups associated with a specific cDNA. Thirty-two unique genes were isolated, sequenced and mapped with the 35 cosmid groups. Three of these cosmid groups generated $\mathrm{cDNAs}$ that were problematic during growth or sequencing. EST/STS primers generated from 24 of 27 clones $(88 \%-$ only three of the nine genes known to map to 17 were used) were found to amplify both the associated cosmid and members of a chromosome 17 somatic cell hybrid panel. These data suggest that three of four cosmids identified by the pooled cDNA probes will be real positives, and the associated cDNA will map to the expected chromosome at a frequency of $90 \%$. 


\begin{tabular}{|c|c|c|c|c|}
\hline cDNA & Cosmid & Similarity & $\mathrm{ACC \#}$ & Position \\
\hline $9 \mathrm{H} 4$ & $65 G 1$ & Human ubiquitin & M26880 & $\mathrm{Xp} 22.2$ \\
\hline $2 \mathrm{~A} 11 / 2 \mathrm{E} 8$ & $78 \mathrm{H} 10$ & Human HMG-17 & $\mathrm{X} 13546$ & $\mathrm{Xp22.1}$ \\
\hline $\mathrm{xp22G3}$ & $250 \mathrm{Al}$ & Human pyruvate dehydrogenase & HUMPYDH & $\mathrm{Xp} 22.1$ \\
\hline $\mathrm{xh95C10}$ & $49 \mathrm{H} 4$ & Human dystrophin & HUMDYS & $\mathrm{Xp} 21.1$ \\
\hline $13 G 8$ & 152B1 & Human monoamine oxidase & X60819 & Xpl1.3 \\
\hline $12 B 5$ & $11 G 7$ & Mouse initiation factor 4AII & X56953 & $\mathrm{Xp} 11.2$ \\
\hline xp519 & 210G5 & Mouse MOPC gene & M11515 & $\mathrm{Xp11.2}$ \\
\hline $11 \mathrm{~B} 6$ & $22 \mathrm{E} 7$ & EST03649 & T03649 & $\mathrm{Xp} 11.2$ \\
\hline $2 \mathrm{D} 9$ & $150 G 11$ & Human cytoskeletal gamma actin & $\mathrm{X} 04098$ & $\mathrm{Xp} 11.2$ \\
\hline $18 G 2 / 9 G 12$ & $230 \mathrm{~B} 5$ & Human cytokeratin 8 & X74929 & Xp11.1-q11 \\
\hline $14 \mathrm{CI}$ & $131 \mathrm{~A} 10$ & Human moesin & M69066 & $\mathrm{Xq12}$ \\
\hline $10 C 7$ & 7F4 & Human haptoglobin related protein & M69197 & Xq12-q13.1 \\
\hline $9 \mathrm{~F} 3$ & $185 \mathrm{G} 3$ & Human homolog of mouse P21 & X64899 & $\mathrm{Xq13}$ \\
\hline $5 G 12 / x p 1515$ & $\begin{array}{l}147 \mathrm{~A} 10 \\
133 \mathrm{D} 1 \\
22 \mathrm{D} 2 \\
27 \mathrm{D} 5 \\
90 \mathrm{G} 4 \\
\end{array}$ & Human elongation factor 1 alpha & X03558 & $\begin{array}{l}X q 21.1-21.2 \\
X q 21+q 25+q 27.3 \\
X q 22 \\
X q 23 \\
X q 27.3-q 28 \\
\end{array}$ \\
\hline $2 \mathrm{G} 6$ & $128 \mathrm{G} 2$ & Human initiation factor $4 \mathrm{AI}$ & D13748 & $\mathrm{Xq} 21.3+\mathrm{Yp} 11.3$ \\
\hline $\mathrm{Xp22F9}$ & $111 \mathrm{C9}$ & Human alpha galactosidase & HUMGALX & $\mathrm{Xq22}$ \\
\hline 3B4 & 197E11 & Human vacuolar proton ATPase & $\mathrm{X} 71490$ & $\mathrm{Xq} 24$ \\
\hline $6 \mathrm{~B} 10$ & 127E9 & Human ADP/ATP translocase & $\mathbf{J} 03591$ & $\mathrm{Xq} 24-\mathrm{q} 25$ \\
\hline$x p 278$ & $236 \mathrm{D} 6$ & Human $\mathrm{Ku}$ autoantigen & S38729 & Xq27.3-q28 \\
\hline$x p 161$ & $231 \mathrm{E} 6$ & Human iduronate 2-sulphatase & M58342 & $\mathrm{Xq27.3-q28}$ \\
\hline $1 \mathrm{~F} 11 / \mathrm{xp} 22 \mathrm{~F} 2$ & $155 \mathrm{E} 7$ & ESTHSAAACDCK & Z20438 & $\mathrm{Xq27.3-q28}$ \\
\hline $\mathrm{xp} 428$ & $92 G 1$ & Human pregnancy specific beta glycoprotein & M93705 & $\mathrm{Xq} 27.3-\mathrm{q} 28$ \\
\hline $6 G 6$ & 189D3 & Human cytokeratin 18 & $\mathrm{X} 12883$ & $\mathrm{Xq} 27.3-\mathrm{q} 28$ \\
\hline $3 \mathrm{Al}$ & $52 \mathrm{G} 10$ & Human DXS1357E & 231696 & $\mathrm{Xq} 27.3-\mathrm{q} 28$ \\
\hline $7 \mathrm{~B} 11$ & $4 \mathrm{~B} 4$ & Gallus filamin & U00147 & $\mathrm{Xq} 27.3-\mathrm{q} 28$ \\
\hline $6 \mathrm{G} 3$ & $78 \mathrm{~B} 10$ & Human MPP1 & M64925 & $\mathrm{Xq} 27.3-\mathrm{q} 28$ \\
\hline
\end{tabular}

Table 1. X-associated cDNAs exhibiting significant similarity with sequence database entries. cDNAs and cosmid names are provided along with the highest match in the database and accession number. Locations of cosmid clones determined by FISH are provided. Genes in bold type were previously known to map to the $\mathrm{X}$ chromosome.

The sensitivity of hybridization with a pooled cDNA probe is an important parameter. If a single clone in a large pool is incapable of identifying its corresponding cosmids, this transcript will be missed by the method. Clone redundancy was measured for positive cDNAs in the chromosome 17 pilot. Of the 32 positive cDNAs, 15 were found in single copy in their respective pools of 864 , while 11 were in two copies, two were in three copies, one had four copies and one each had seven and eight copies. Clearly, cDNAs in single copy in the pool are capable of identifying corresponding cosmids. 


\begin{tabular}{|c|c|c|}
\hline cDNA & Cosmid & Location \\
\hline 7D8 & $93 \mathrm{~B} 6$ & $X p 22.3+Y p 11.3$ \\
\hline $3 G 12$ & $\begin{array}{l}93 \mathrm{~B} 6 \\
152 \mathrm{G} 7 \\
127 \mathrm{E} 9\end{array}$ & $\begin{array}{l}\text { Xp22.3 +Yp11.3 } \\
\text { Xp11.2 } \\
\text { Xq24 }\end{array}$ \\
\hline xp664 & $14 \mathrm{G} 3$ & Xpl1.3-p11.2 \\
\hline 8D1 & $\begin{array}{l}47 \mathrm{G} 2 \\
27 \mathrm{C} 7\end{array}$ & $\begin{array}{l}X p 11.2 \\
X q 23\end{array}$ \\
\hline $\operatorname{xp} 587$ & $2 \mathrm{C} 11$ & $\mathrm{Xq} 22$ \\
\hline $6 \mathrm{~A} 11$ & $122 \mathrm{H} 2$ & Xq22 \\
\hline 12D8 & 70B7 & Xq23-24 \\
\hline $7 \mathrm{E} 7$ & 197E11 & Xq24 \\
\hline xp464 & 33B2 & $X q 24-25$ \\
\hline
\end{tabular}

Table 3. $X$-associated cDNAs exhibiting no similarity with sequence database entries. cDNAs and cosmid names are provided with locations of cosmid clones determined by FISH are provided.

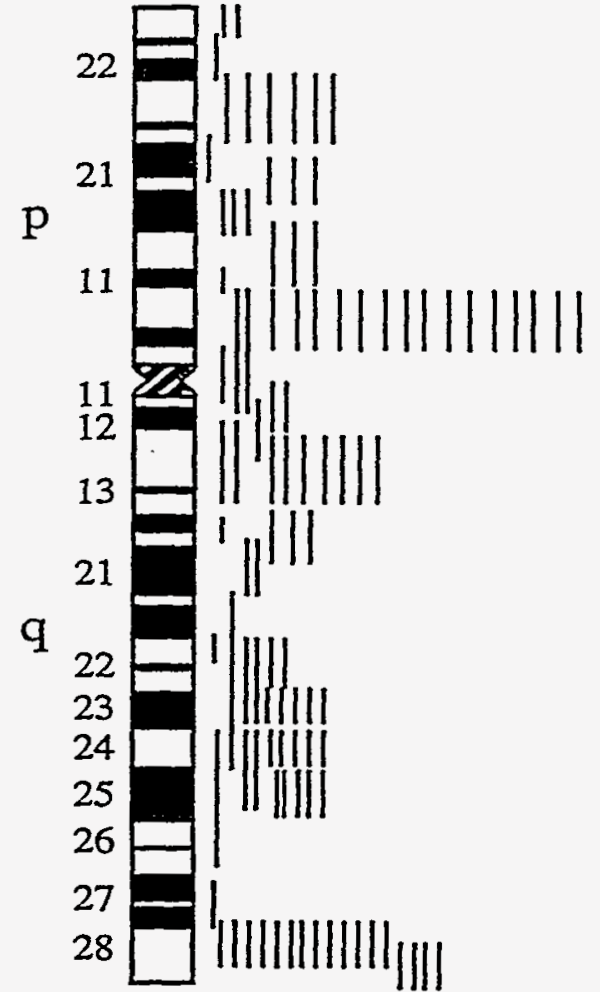

Figure 1. Positions of geneassociated cosmids mapped by FISH (103 total).

A scaled-up series of experiments is in progress, with a goal of $60,000 \mathrm{cDNAs}$ to be analyzed in the same two genomic libraries. Two-thirds of these cDNAs $(40,000$ placental and heart clones) have been grouped into 46 pools of 864 clones each, and used as probes on the LLNL library. A total of 2848 cosmids were identified and isolated as individual clones. This represents over 10\% of the clones in the library-a substantial proportion of the chromosome. Cosmids associated with each cDNA pool were re-arrayed for further manipulation. Individual back hybridization of the cosmids is impractical, so cosmids have been grouped into pools of ten (pilot studies demonstrated the feasibility of this approach with known positives) for hybridization to the cDNA filters. To date 130 cosmid pools have been used, identifying nearly 400 potential X-specific cDNAs. To identify individual cDNA-cosmid associations, cDNA clones identified will be individually hybridized to the rearrayed cosmid clones. The total number of hybridizations required by this method to identify the cDNAs with $X$ chromosome association from the initial $40,000 \mathrm{cDNA}$ clones is estimated to be $\sim 1000$ (46 initial cDNA pools; 285 cosmid pools; 800 individual cDNAs). This is a large number of hybridizations, but is manageable, especially when considering that the targets for hybridization are successively smaller in subsequent experiments. For example, the initial cDNA pool probes are applied to 25,000 clones, the cosmid probes are applied to an 864 clone array, and the individual CDNA probes are used against the cosmids identified by their parent pool (average of $\sim 60$ cosmids). Thus the scale and difficulty of each hybridization step is successively reduced.

At the present time over 100 unique cDNA-cosmid associations have been made (including those described in the pilot studies) for the $\mathrm{X}$ chromosome. The majority of the cosmids have been mapped by FISH (Figure 1), and cluster into three major regions already known to be gene rich (Xp11, Xq13 and Xq28). EST/STS primers have been generated from 52 of the CDNA sequences. These primers amplified the associated cosmid for $28 / 52(54 \%)$ cDNAs. Not included in this analysis were nine genes previously assigned to the $\mathrm{X}$ chromosome. Taking these nine into account, 37 of $61(60 \%)$ cDNAs isolated clearly derive from the $X$ chromosome. This number is 
somewhat lower than that found for chromosome 17 , which may reflect a difference in the number of gene families and/or pseudogenes present on the $\mathrm{X}$ chromosome. Nevertheless, these data suggest that six of ten $\mathrm{cDNAs}$ isolated by the reciprocal probing method will be derived from the $\mathrm{X}$ chromosome, a significant enrichment over mapping cDNAs at random.

If the 800 potential cDNAs identified in these studies follow this pattern, then $\sim 350$ will truly be $\mathrm{X}$-specific after the redundancy in the cDNA library is taken into account. This represents a two-fold increase over currently known genes. To generate this number of unique cDNAs mapped to the $\mathrm{X}$ through random assignment of $\mathrm{cDNAs}$ to chromosomes would require mapping of 7000 perfectly normalized $\mathrm{cDNAs}$, an effort whose scale has not been approached. Another major advantage of the method is that it directly provides one or more genomic clones for the locus of i.tterest. Since a reference cosmid library is used, it offers the ability to immediately check for information regarding the clone under study, even at the stage of initial identification of the cosmid with the cDNA pool.

Parallel efforts in the laboratories of Drs. David Nelson, Huda Zoghbi, Andrea Ballabio, and A. Craig Chinualt have aimed to establish physical map data for the LLNL flow sorted X cosmids. Through the NIH funded BCM genome center, informatics systems for managing the coordination of these data have been developed. Grid positions of cosmids identified either by YAC hybridization or reciprocal probing is entered and maintained in a Sybase database, the Cosmid Relational Data Base (CRDB). The LLNL library is composed of $\sim 24,000$ clones, and data regarding over 8000 of these has been developed thus far. The physical map data is largely found for clones in the distal $\mathrm{Xq}$ and $\mathrm{Xp}$ regions, with some efforts in proximal Xq as well. Crossreferencing of these data offers ready identification of fine-scale map positions for genomic clones associated with cDNA clones, simplifying and refining the mapping of the genes giving rise to the cDNAs.

From about 1300 of these cosmids, 206 unique cDNA-cosmid associations have been established, approximately doubling the number described in the preliminary publication. Of these $206 \mathrm{cDNAs}-$ cosmid associations, 78 were from a heart cDNA library and 128 were from the placenta library. YAC probing of the cosmid library has revealed over 1000 "common" cosmids also identified by the cDNAs pool probes by querying the CRDB. In the majority of cases, several cosmids found to be in a common physical mapping interval (bin) are positive with the same cDNA. This offers substantial evidence of the validity of both the bin assignment and the cDNA assignment.

Numerous examples in both Xq and Xp have been found, and many of these have been taken to paired genomic/cDNA sequence to establish the identity of the coding sequence.

Continuing efforts in these areas are focused on continued YAC-association of cosmid clones in preparation for long-range sequencing, and further characterization of the associated cDNAs to define the gene content of these regions of the $\mathrm{X}$ chromosome. No additional cDNA libraries are being used in these efforts due to inadequate funding. 


\section{Students trained:}

Matt Mulloy (summer undergraduate student)

\section{Postdoctoral fellows supported:}

Ali Yazdani, M.D. (in clinincal training)

Zhouyang Zhao, Ph.D. (in postdoctoral training)

\section{Publications (*indicates specific citation of support)}

*Ferrero, GB, Franco, B, Roth, EJ, Firulli, BA, Borsani, G, Delmas-Mata, J, Weissenbach, J, Halley, G, Schlessinger, D, Chinault, AC, Zoghbi, HY, Nelson, DL, Ballabio, A (1995) An integrated physical and genetic map of a $35 \mathrm{Mb}$ region on chromosome Xp22.3-Xp21.3. Hum Mol Genet, in press.

*Lee, CC, Yazdani, A, Wehnert, M, Zhao, Z, Lindsay, EA, Bailey, J, Coolbaugh, M, Couch, L, Xiong, M,
Chinault, AC, Baldini, A, Caskey, CT Chinault, AC, Baldini, A, Caskey, CT. (1995) Isolation of chromosome-specific genes by reciprocal probing of
arrayed cDNA and cosmid libraries. Hum Mol Genet, 4:1373-1380.

Zhao, Z, Lee, CC, Baldini, A, Caskey, CT. (1995) A human homologue of the Drosophila polarity gene frizzled has
been identified and mapped to 17q21.1. Genomics, 27:370-373.

Zhao, Z, Lee, CC, Jiralerspong, S, Juyal, RC, Lu, F, Baldini, A, Greenberg, F, Caskey, CT, Patel, PI. (1995) The gene for a human microfibral-associated glycoprotein is commonly deleted in Smith-Magenis syndrome patients.
Hum Mol Genet, 4:589-592.

\section{DISCLAIMER}

This report was prepared as an account of work sponsored by an agency of the United States Government. Neither the United States Government nor any agency thereof, nor any of their employees, makes any warranty, express or implied, or assumes any legal liability or responsibility for the accuracy, completeness, or usefulness of any information, apparatus, product, or process disclosed, or represents that its use would not infringe privately owned rights. Reformanufacturer, or otherwise does not necessarily constament or any agency thereof. The views mendation, or favoring by the United Stan do not necessarily state or reflect those of the and opinions of authors expressed herein do 